\title{
PREVENTION AND CONTROL OF CUTTING-OIL DERMATITIS
}

\author{
BY \\ EDWARD COLLIER \\ Glasgow
}

Of the chief industrial hazards to which employees in this country are exposed, the one to show the greatest increase during the past few years as regards numbers affected is dermatitis ' caused by dust or liquids.' One of the obvious reasons is related to the marked increase in the number of workers who are engaged in the heavy industries, engineering and munitions, and therefore in contact with various kinds of skin irritants. In a large engineering establishment where the writer is medical officer, the chief industrial hazard is oil dermatitis. The methods and measures adopted to control this hazard, and the results obtained during the past three years, may therefore be of interest.

\section{Types of Oil}

The three commonest types of oils with which workers come in contact are soluble oil, lard oil and paraffin oil. These are used on the engineering side as follows. Soluble oil, which is water soluble, is used as a coolant in operations where great heat is generated. Lard oil is used as a lubricant and in operations where the sharp edges of the tools have to be preserved. Paraffin oil is also used as a lubricant and as a degreasing agent in the form of a wash.

There are various types of soluble oils used in engineering establishments and the one most commonly in use at the writer's factory consists of a mineral oil and animal or vegetable oil with the addition of an emulsifier, such as soap. A trace of a phenolic disinfectant (p. tertiary amyl phenol) is added by the supplier.

Analysis of this type of oil reveals the following:

\begin{tabular}{|c|c|c|c|c|}
\hline Saponifiable matter . & & & 3.00 & $r$ cent. \\
\hline Unsaponifiable matter & & & $* 84 \cdot 10$ & \\
\hline Ash $\quad \ldots \quad \ldots$. & & & 1.07 & \\
\hline Water (by difference). & & & $11 \cdot 83$ & \\
\hline Acid value $\cdots$ & . & .. & $4 \cdot 9$ & , \\
\hline Contains fatty oils & . & $\cdots$ & $12 \cdot 6$ & , \\
\hline Sp. Gr. at $18^{\circ} \mathrm{C}$. & . & & 0.940 & , \\
\hline Phenols $\quad$.. & $\cdots$ & & Presen & \\
\hline
\end{tabular}

As already mentioned soluble oil is used for its cooling properties and in the strength of a 4 per cent. solution appears as a whitish opalescent mixture. Of the three oils in use, soluble oil has led to least trouble regarding the incidence of dermatitis. Lard oil is used neat and contains 40 per cent. mineral oil and 60 per cent. pure lard oil. No sul- phur or soluble disinfectants are present, as in some lard oils used in other branches of engineering. Paraffin oil is also used neat and a sample taken from bulk stock reveals the following:

$$
\begin{aligned}
& \begin{array}{lllll}
\text { Sp. Gr... } & \ldots & \ldots & \ldots & 0.800
\end{array} \\
& \begin{array}{llll}
\text { Organic acidity } & \ldots & \ldots & \text { Nil }
\end{array} \\
& \begin{array}{lllll}
\text { Inorganic } & \ldots & \ldots & \ldots & \text { Nil }
\end{array}
\end{aligned}
$$

\section{Effects Produced}

The commonest type of oil dermatitis seen during the past three years has been an oil acne caused either by lard oil itself or a mixture of lard oil and paraffin oil. As a result of the mechanical blocking of the sebaceous glands and hair follicles, chiefly of the arms and legs, papules form which, if they remain untreated or are further exposed to the irritating effects of the oils, become complicated in the form of folliculitis which if carried a stage further can go on to furunculosis.

The chief types of lesions produced by soluble oil are, in more acute cases, a diffuse macular and papular rash over the arms and legs; in more chronic cases an oil acne, which is usually not so marked as that produced by lard oil. Paraffin oil dermatitis takes the form, in the first stage, of an erythema of the area in contact with the oil. If allowed to go untreated, the skin becomes dry and fissures may form. In other cases, desquamation of the skin occurs; a more severe degree results in vesiculation on the erythematous area. The commonest sites for oil dermatitis are on the forearms and anterior aspects of thighs and legs, and around the anterior aspects of the elbows.

As already mentioned, the chief factor of the production of oil dermatitis or oil acne is the mechanical blocking of the sebaceous glands and hair follicles. This is largely contributed to by neglect of personal cleanliness and by the friction of oil-soaked overalls on the arms and legs. In the cases of paraffin and soluble oils, where the arms and legs may be wetted for a considerable period of time by contact with the oils, the wetting results in a weakening of the resistance of the skin and the onset of a diffuse macular and papular rash over the areas.

\section{Prevention}

The chief measures which have been adopted, are -(1) selection of suitable employees; (2) education of the workers; (3) measures on the job. 
Selection of Suitable Employees. All employees before being interviewed by the staff of the Labour Department fill up a form which asks, among other things, whether the individuals have had a previous attack of dermatitis; its duration; if it was sufficiently serious to incapacitate them from work; period of incapacity; and whether compensation was successfully claimed or not. In the medical examination of suitable applicants for work, points which are looked for are, (1) good thickness of skin, (2) the skin not to be too dry or too greasy, (3) no evidence of skin lesions.

It is well recognized that an attack of dermatitis caused by a specific irritant, whether physical, chemical or bacterial, sensitises the skin and makes individuals more susceptible to further attacks if they continue to be in contact with skin irritants. Individuals who apply for work where they will be in contact with oil and who give a previous history of dermatitis which has incapacitated them for some time (weeks or months), whether industrial or nonindustrial in origin, are therefore recommended for a type of work, if available, where they will not be in contact with oils. This is particularly the case where the workers are fair-haired and pale or redskinned. It is the writer's experience that such individuals. have skins which are more sensitive to irritants than those of darker brown-skinned persons. This question of sensitization of skin, with increased susceptibility to further attacks of skin trouble, is well illustrated by the following case.

M. McL. was first seen on 1.11 .40 when she gave the following history. Six years previously, when she was working in a bakery, she developed dermatitis of the face, arms and neck, caused by sugar and flour with which she was in contact. She was off work for 6 weeks and received compensation. She started work on 3.6 .40 before pre-employment selection had been instituted and, working at that time with soluble, lard, and paraffin oils, she soon developed acute pustular dermatitis of both arms with a papular dermatitis of the face. She was suspended from work and was off work for two years. Her second attack of occupational dermatitis proved most resistant to all forms of treatment.

Education of the Workers. Propaganda regarding preventive measures starts as soon as the successful applicants are ready to commence work when they are given a leaflet stressing the following points:

Personal Cleanliness. - They are advised to wash, particularly their hands and forearms, at tea breaks and at meal times. Ample facilities for washing with hot and cold water are available for all employees.

Protective Lotions.-The leaflet also advises all employees that protective lotions are supplied free from every first-aid room in the factories. If working with soluble oil, they should ask for Alkaline Wash; if working with paraffin oil, they should ask for what the writer calls Dermis Wash, to contrast with Alkaline Wash. The respective formulae of these washes are:
Alkaline Wash

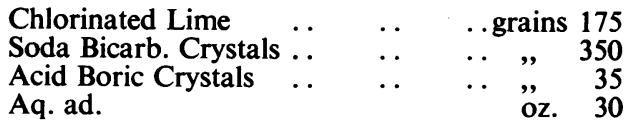

Dermis Wash

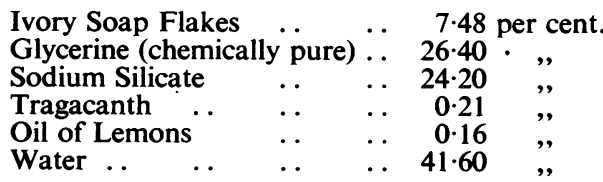

The paste thus formed is dissolved in water in the proportion of $2 \frac{1}{2} \mathrm{lb}$. of paste to 2 gallons of water.

Further advice is given in the leaflets to use these washes after getting home from work and before starting out in the morning, as follows:

1. Dilute the wash 1 part to 10 parts of water.

2. Apply the wash to your hands, arms, etc.

3. Wash your hands, arms, etc., with hot water and soap (not carbolic). Dry them thoroughly.

This will remove all traces of oil from your skin and will prevent the onset of dermatitis.

N.B.-Oil dermatitis is not infectious.

By means of these leaflets all workers who will be in contact with oil are made aware, from the first day they start, of the value of personal cleanliness and of the availability for all who need them of protective skin lotions In spite of the large number of barrier creams and ointments at present on the market, the writer has not found anything the action of which is better than these lotions.

Overalls.-In February 1941 when the system of distribution of overalls was changed, the opportunity was taken to give all workers a leaflet with their new overalls, stressing the importance of changing overalls at least once a week and stressing the part played by friction of oil-soaked overalls on the skin of the arms and legs, as a consequent factor of producing oil dermatitis. Since then difficulties have arisen regarding frequent changing and replacing of overalls because of their coupon value and because of increasing laundry difficulties.

Propaganda.-Verbal propaganda is also undertaken by the first-aid and nursing staffs, stressing the above-mentioned factors to all employees who report to the various first-aid rooms with rashes, whether industrial or non-industrial in origin. An example where such propaganda has proved of value has been particularly among inspectresses, who have sitting jobs and have been leaning with arms akimbo on oil-moistened benches, with the result that rashes have appeared on the parts in contact with the oil. These rashes, seen in the early stages, have been treated and the moral pointed out to the girls. Lectures on the factors underlying the prevention of oil dermatitis have been given to apprentices on the principle of 'catching them young.' Other forms of propaganda are by means of posters stressing on workers to report to the nearest first-aid room as soon as they find evi- 
dences of a rash. From the numbers of skin cases seen, there must be very few employees in this organization who do not do this. There is no doubt that the official posters dealing with oil dermatitis are not emphatic enough in their appeal and are too verbose to have much value as propaganda. Finally, propaganda measures are intensified during the summer months when rashes of all kinds are commonest.

Measures on the Job. By co-operation with the superintendents and their supervising staffs, the following measures are attended to:

1. Changing the oils as frequently as they become dirty.

2. Adequate cleansing of oil containers as often as necessary.

3. Splash guards on the machines to be adequate.

4. Where required, to see that all workers are supplied with, and encouraged to wear, protective clothing such as oil-proof gloves, aprons and armlets.

5. The oils should be periodically analysed. An outbreak of paraffin oil dermatitis, evidenced

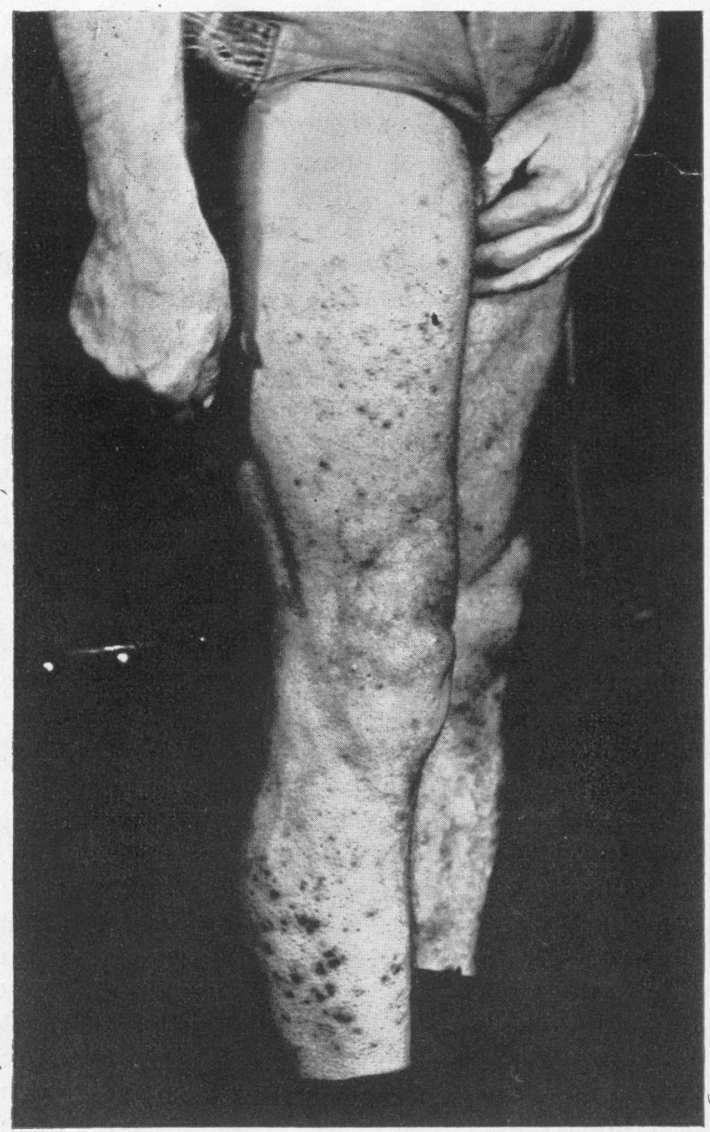

'FIG. 1.-To show lesions of oil acne, folliculitis and furunculosis over lower limbs which were very rarely washed. Note the absence of lesions on hands and forearms which were washed regularly. by erythema of hands with vesiculation of the webs of the fingers, occurred among workmen engaged in one of the paraffin wash sections. The oil was analysed and was found to be contaminated with cresylic acid. Appropriate steps were then taken to eliminate this.

\section{Incidence of Cases}

The measures outlined above have now been established for three years. The number of cases of developed oil dermatitis who have reported for supervision and active treatment every month during this period, have been as follows:

$\begin{array}{ccccccc} & \text { Jan. } & \text { Feb. } & \text { Mar. } & \text { Apr. } & \text { May } & \text { June } \\ 1941 & 53 & 37 & 44 & 30 & 28 & 22 \\ 1942 & 25 & 22 & 43 & 16 & 39 & 20 \\ 1943 & 13 & 15 & 12 & 17 & 30 & 23 \\ & & & & & & \\ \text { July } & \text { Aug. } & \text { Sept. } & \text { Oct. } & \text { Nov. } & \text { Dec. } & \text { TotAL } \\ 30 & 23 & 27 & 25 & 16 & 18 & 353 \\ 12 & 12 & 18 & 15 & 16 & 12 & 250 \\ 11 & 16 & 15 & 18 & 9 & 12 & 191\end{array}$

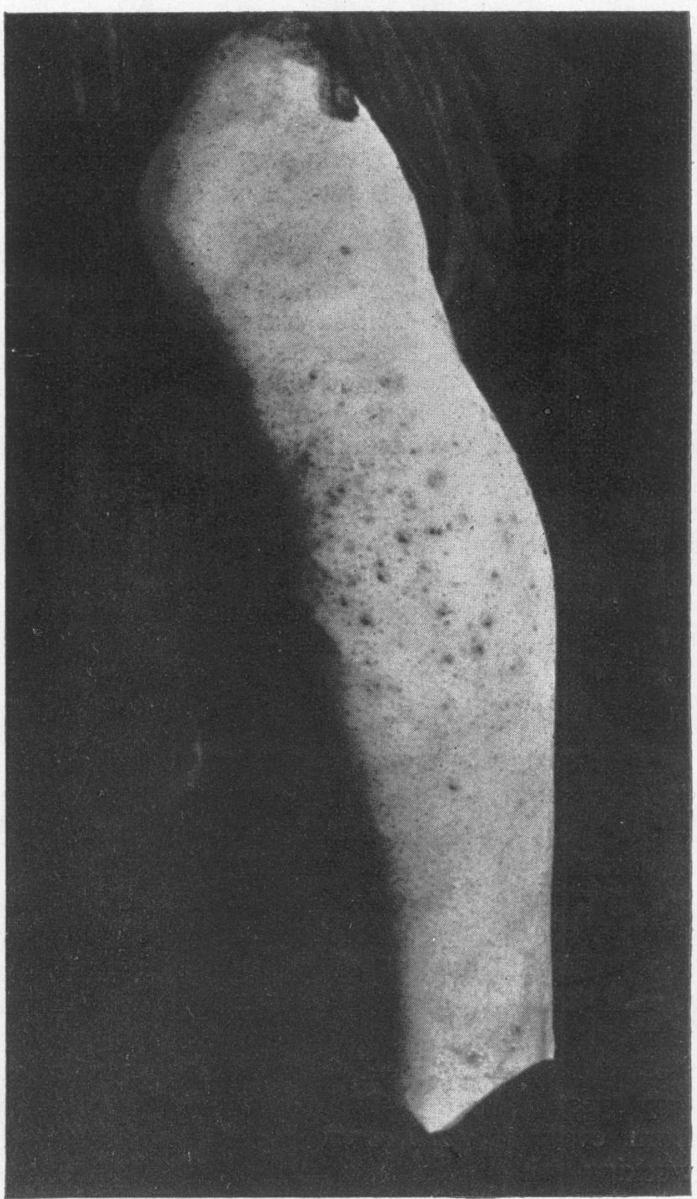

FIG. 2.-To show how friction of oil-soaked overalls produces relatively few lesions on the postero-lateral aspects of the leg where friction is not so great. 
For security reasons, it is impossible to state the number of workers who are exposed to the hazard of oil dermatitis.

During recent months most of the new cases have been among newly engaged labourers who have to clean out the machines and oil containers and whose mental qualities are such that they are not the best material for propaganda and educative measures. The photographs show a very severe degree of oil dermatitis of the legs of one such labourer with plugging of the pilo-sebaceous follicles with oil, and the evidences of oil acne, folliculitis and furunculosis. $\mathrm{He}$ had been cleaning out machines for three months, and although he kept his hands and forearms clean by means of frequent washing and showed no lesions on them he had been very neglectful of the hygiene of his lower limbs, with the results depicted.

\section{Treatment}

Most of our cases of developed oil dermatitis are seen in the early stages, and the most efficacious treatment of oil acne consists in washing the areas with soap and water and applying 1 per cent. gentian violet. The diffuse macular and papular rashes and paraffin erythemas are treated with a lotion containing calamine and ichthyol or zinc and ichthyol cream; then when the condition has improved, the patients are again reminded of the protective measures.

In a small proportion of cases, transfer to a job away from oil is deemed a necessary addition to treatment.

From the measures outlined above it will be seen that the prevention and control of oil dermatitis in industrial establishments requires not only the full assistance and co-operation of the staff of the Medical Department but also those of the Labour Department, supervisory technical staffs, chargehands and foremen, and also the laboratory staff. The doctor, the labour manager, the engineer and the chemist, by team work, can all play their part in reducing the incidence of industrial hazards and particularly, as described above, oil dermatitis. 